\title{
Prevalence and health correlates of workplace violence and discrimination - a cross-sectional study among hospital employees in Switzerland
}

\author{
Alenka Stahl-Gugger \\ Health Directorate of the Canton of Zurich \\ Oliver Hämmig ( $\nabla$ oliver.haemmig@uzh.ch ) \\ Epidemiology, Biostatistics and Prevention Institute of the University of Zurich
}

\section{Research Article}

Keywords: violence, discrimination, workplace, work, health, hospital employees, health professionals, health care

Posted Date: November 22nd, 2021

DOI: https://doi.org/10.21203/rs.3.rs-989580/v1

License: (c) (i) This work is licensed under a Creative Commons Attribution 4.0 International License.

Read Full License 
1 Prevalence and health correlates of workplace violence and discrimination

2 - a cross-sectional study among hospital employees in Switzerland

3

4 Alenka Stahl-Gugger ${ }^{1)}, \mathrm{MD}$; Oliver Hämmig $\left.{ }^{2}\right)^{\star}, \mathrm{PhD}, \mathrm{MPH}$

5

$6{ }^{1)}$ Health Directorate of the Canton of Zurich, Stampfenbachstrasse 30, 8090 Zurich, Switzerland

$7 \quad{ }^{2}$ Epidemiology, Biostatistics and Prevention Institute of the University of Zurich, Hirschengraben

$8 \quad 84,8001$ Zurich, Switzerland

9

$10{ }^{*}$ Corresponding author 
Abstract

\section{Background}

Violence and discrimination are common events at work, especially in the health care setting.

Nevertheless, comprehensive data on their prevalence and health correlates among the entirety of hospital staff is missing. This study aimed to estimate the prevalence of different self-reported forms of workplace violence and discrimination among hospital employees in Switzerland and to investigate the association between such experiences at work and the general and mental health status.

\section{Methods}

This cross-sectional study was based on secondary data from a company survey among five public hospitals and rehabilitation clinics in German-speaking Switzerland conducted in 2015/16 $(\mathrm{N}=1,567)$. Relative frequencies of different forms of violence and discrimination at work were calculated for the entire study population and for the occupational subgroups. These prevalence data were compared with a representative sample of the general Swiss working population as a reference group. Multiple logistic regression analyses were further computed to investigate the association between the number of different experienced forms of violence and/or discrimination at work and several poor general and mental health outcomes (poor self-rated health, sleep disorders, psychological stress, mental problem, burnout).

\section{Results}

$23 \%$ of hospital employees experienced at least one form of discrimination or violence at work in the past year, compared to $18 \%$ of the general working population. Nurses and midwives were by far the most affected occupational group regarding all forms of violence. More and particularly most exposed hospital employees with regard to experiences of violence and/or discrimination at work showed almost consistently increased prevalence rates and odds ratios for the studied poor mental and general health outcomes. Prevalence rates and adjusted odds 
ratios for strong sleep disorders, strong stress feelings and increased burnout symptoms were between three and four times higher among the most exposed compared to those hospital employees who did not make any of these experiences at work at all.

\section{Conclusions}

Study findings underline the importance of an active combat against violent and discriminatory behaviors in health care. Prevention strategies should particularly focus on nurses and midwives, which turned out to be the most affected and exposed group of all health professions.

\section{Keywords}

violence, discrimination, workplace, work, health, hospital employees, health professionals, health care

\section{Background}

Workplace violence and discrimination are major and growing problems, which can be found in virtually all of the occupational groups $(1,2)$. The International Labour Organization (ILO) of the United Nations defines workplace violence as "any action, incident or behavior that departs from reasonable conduct in which a person is assaulted, threatened, harmed, injured in the course of, or as a direct result of, his or her work" (3). Discrimination on the other hand is defined by the ILO as "any distinction, exclusion or preference made on the basis of race, color, sex, religion, political opinion, national extraction or social origin, which has the effect of nullifying or impairing equality of opportunity and treatment in employment or occupation" (4). Discrimination adversely affects human rights (4).

There are many different forms of discrimination and violence. The latter can be divided into a physical, a psychological and a sexual dimension according to the ILO (3). Additionally, a distinction between internal (between employees) and external violence (between an employee and another person present at work) can be made (1). Health professionals are especially 
affected from workplace violence with a prevalence in an international comparison up to $17 \%$ for physical and up to $67 \%$ for psychological violence within a year $(5,6)$. Sexual harassment during the occupational career was reported by every second academic medical faculty women in the United States (7). Previous evidence suggests a prevalence of discrimination in hospital workers around $14 \%$ during the past year (8).

However, the true extent of workplace violence in the health care sector is difficult to assess, as a high number of unreported cases must be assumed (9). Reasons for systematic underreporting might be that employees do not anticipate a change by the reporting of violence experiences (10) or they underestimate its negative consequences (11). Underreporting is a particular problem in health workers with direct patient contact, as they tend to excuse the behavior of their attackers, for example due to the mental status, pain or emergency situation of their patients (12).

There is evidence that workplace violence and discrimination among health professionals have a huge (public) health impact. A systematic review revealed a broad range of negative consequences of workplace violence in the health care setting, which can be divided into seven categories: physical consequences (direct injuries of the body), psychological consequences (as depressive symptoms), emotional affecting (as anxiety), adverse effect on the workplace functioning (as decrease in productivity), negative impact on health care quality (as patient safety), social consequences (on private and family life) and financial consequences (as the loss of income due to absences from work) (13). Similarly, a meta-analysis on the effect of workplace discrimination due to race showed a negative impact on the attitude to work and on the physical and psychical health of the affected persons (14).

Many of the above-mentioned consequences of workplace violence and discrimination obviously have a detrimental effect not only on an individual level, but also on a company level and on the societal level. While longer sick leaves and absences from work may be the most important factors for the company, a loss of quality in health care has a serious impact on the society as a whole. Furthermore, as health professionals usually face high work demands, a 
loss of productivity in consequence of experiencing violence at work is a serious challenge in health care.

In the Swiss Health Survey from 2017 the experience of at least one form of violence or discrimination at work in the previous year was reported by $21.1 \%$ of women and $17.5 \%$ of men, with an increase in both sexes compared to the previous survey in 2012 (15). Although workplace violence and discrimination have been identified and recognized as a common phenomenon in the health care sector, the prevalence and health correlates of this specific psychosocial risk factor among health care workers are largely unexplored and underresearched, particularly in Switzerland. For this reason, the present study has been conducted, based on survey data collected among hospital employees and particularly health professionals from German-speaking Switzerland.

Against the background of the lack of evidence in this regard, this study aimed to investigate the following research questions:

1. What is the prevalence of different aspects and accumulated experiences of workplace violence and discrimination among hospital employees and particularly among health professionals in Switzerland, and in comparison with the entire working population?

2 . Is there consistently a pronounced and negative association and a halfway linear doseresponse relationship between accumulated experiences of workplace violence and/or discrimination on the one hand and different health outcomes on the other hand among hospital employees?

Figure 1 illustrates the theoretical path model of the postulated association between experienced workplace violence and/or discrimination and health status, which is assumed to be potentially confounded by chronic disease.

\section{Figure 1}

Theoretical path model showing the assumed and studied associations between exposure, outcome and confounding variables 
Workplace Violence \&

Discrimination

- Verbal Violence

- Threats and Humiliation

- Physical Violence

- Intimidation or Mobbing

- Sexual Harassment

- Discrimination due to Age

- Discrimination due to Gender

- Discrimination due to Nationality,

Ethnicity or Skin Color

- Discrimination due to Disability

\section{General \& Mental Health}

- Poor Self-rated Health

- Sleep Disorders

- Psychological Stress

Mental Problem (Treated)

- Burnout Symptoms
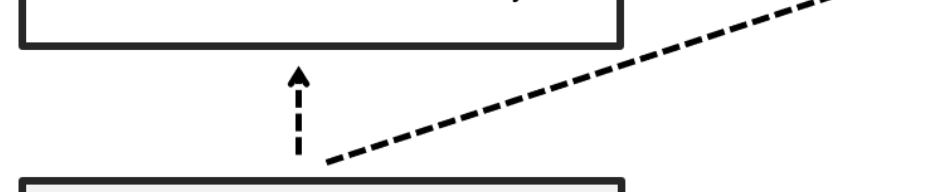

\section{Chronic Disease}

\section{Methods}

\section{Sample and procedure}

This single sample, cross-sectional, quantitative study design is based on a company survey, which was administered to five hospitals in German-speaking Switzerland in 2015 and 2016.

The hospitals participating in the survey were selected by convenience sampling (nonprobability sampling) and included one university hospital, one cantonal hospital, one district hospital and two rehabilitation clinics. The size of hospitals varied between 480 and 2,200 permanent employees. The self-administered paper-and-pencil questionnaire included 100 questions in total and took about 30 minutes to complete. Its overall aim was to gather information on working conditions and health of hospital employees.

All permanent employees of the selected hospitals received the survey. Thus, no restriction was made concerning the different professions working in a hospital, hierarchical levels or business units. Employees were allowed to fill out the survey during working time, but could also take it home to complete if preferred. Individuals were asked to send the questionnaire back to the 
researchers by a prepaid reply envelope within four weeks, and got a reminder one week before submission deadline. For the statistical analysis, 1567 completed questionnaires were available, corresponding to an overall response rate of $41 \%$. The response rates ranged from $36 \%$ to $49 \%$ between the participating hospitals.

\section{Measures}

\section{Exposure variable(s)}

Violence and discrimination at work. Experiences of workplace violence and discrimination were measured by the question "Have you experienced the following in the past 12 months at work?" with a note that multiple answers were possible. Ten answer categories were given:

"discrimination due to age", "discrimination due to gender", "discrimination due to nationality, ethnicity or skin color", "discrimination due to disability", "verbal violence", "threats and humiliation", "physical violence", "intimidation or mobbing", "sexual harassment", and "none of them". The question and response options were adopted from the Swiss Health Survey, allowing to make a direct comparison with secondary survey data representing the working population of (German-speaking) Switzerland (15). For the association analyses, a sum scale which simply adds up the number of experienced and surveyed different aspects of workplace violence and/or discrimination was constructed. The sum scale starting with 0 and a possible maximum score of 10 was classified into three categories of "none" (0), "a single" (1) and "two or more" (2+).

\section{Outcome variables}

General and mental health. With the exception of burnout, which was assessed by an established multiple-item measure, single-item measures were utilized to assess the general and mental health status of the study population of hospital employees. Most of these widely used items were taken from the Swiss Health Survey, allowing to make a comparison with a representative sample of the working population in German-speaking Switzerland. 
- Self-rated health. Self-reported general health status was measured by asking "How is your health status in general?" with response categories from 1 ("very good") to 5 ("very bad"). Self-rated health ( $\mathrm{SRH})$ is an established and well-validated measure of general health, showing a strong association with both mortality (16) and morbidity (17). Due to its strongly skewed distribution, SRH was dichotomized (and binary coded) into two categories, combining answers from "very good" and "good" (value 0) and from "moderate" to "very bad" (1), labeled as "poor SRH", as suggested by the research literature (18).

- Sleep disorders. Sleeping problems were assessed by asking the respondents about having had complaints in the past four weeks such as difficulties in falling asleep or sleeping through, with three answer categories dichotomized into "none at all/only a little" (0) and "strong" (1), in order to calculate logistic regression analyses.

- Psychological stress. General stress in a psychological (and not physiological sense) was measured by a given definition ("Stress means a condition in which a person feels tense, restless, nervous or anxious or is unable to sleep at night because his/her mind is troubled all the time."), followed by the question: "Did you feel stressed in the past 12 months?" For the analysis, response categories, initially on a five-point Likert Scale from 1 ("not at all") to 5 ("very strong"), were then dichotomized and binary coded, distinguishing between 0 "less stressed" ("not at all”, "a little", "moderate") and 1 "strongly stressed" ("strong", "very strong"). This single-item measure of general stress is a widely used and well-validated indicator of mental strain (19).

- Mental problem. In order to measure a psychological problem, survey participants were directly asked if they had been treated due to a mental problem in the past 12 months, with the answer options "no" (0) and "yes" (1).

- Burnout. Burnout symptoms were measured using the 6-item subscale of personal burnout from the Copenhagen Burnout Inventory ( $\mathrm{CBI})(20)$. The German version of this scale asks about the frequency of feeling tired, of being physically exhausted, of being emotionally exhausted, of thinking "I can't go any longer", of being drained, and of feeling weak and vulnerable to diseases. Each item can be answered on a five-point Likert scale ranging from 

0 ("never") to 4 ("always"). The sum score out of these answers of the CBI was calculated and ranged between 0 and 24, with values above 16 being considered as an increased risk of burnout.

\section{Confounding variable}

Chronic disease as a potential confounder was measured by the question "Do you have a chronic disease or health problem?" (yes/no), followed by the explanation that this is a condition which is already lasting or still ongoing for at least 6 months.

\section{Control variables}

Sex, age and education were used as control variables. Age was measured by asking about the age category the respondent belongs to ( $<25$ years, $25-34$ years, $35-44$ years, $45-54$ years and $\geq 55$ years). Education was measured by asking participants about their highest degree of education. The 12 given educational qualifications were categorized into four levels of education: 1 "low" (no vocational education), 2 "medium" (basic vocational education/apprenticeship), 3 "high" (higher vocational education or high-school diploma), and 4 "very high" (university degree).

For stratified analyses or rather differentiated descriptive statistics, study or survey participants were further categorized into four occupational groups (nurses and midwives, physicians and other academics, medical-therapeutic and medical-technical staff, administrative and other service staff).

\section{Analyses}

To answer the first research question regarding the prevalence rates of workplace violence and discrimination among health care workers in German-speaking Switzerland, relative frequencies of exposure variables (single items and sum scale of different aspects of workplace violence and discrimination) were calculated for the entire study population and additionally stratified by the four occupational groups. Such descriptive statistics were provided for the study sample as 
well as for the comparable and representative subsample of the Swiss Health Survey of 2017 as a reference group.

Multiple logistic regression analyses were then performed to study the second research question about the assumed and possibly confounded association and dose-response relationship between the accumulated number of experiences of violence and discrimination at work and different general and mental health outcomes. More precisely, multiple adjusted odds ratios (aOR) were calculated to estimate the relative and health-related risk of such experiences in the study population.

\section{Results}

\section{Descriptive statistics}

The prevalence of experiences of different forms or aspects of violence and discrimination at work among hospital employees (in the past twelve months) is shown in Table 1. With a look at the entirety of hospital employees, the most frequently reported form of discrimination was due to age $(5 \%)$, followed by discrimination due to gender $(4 \%)$, nationality, ethnicity or skin color (3\%) and disability (less than 1\%). In physicians and other academic staff, discrimination due to gender was the most prevalent form (8\%).

With regard to experiences of violence at work among the studied hospital employees, intimidation or mobbing was the most commonly reported form (10\%), followed by verbal violence $(7 \%)$, threats and humiliation $(5 \%)$, sexual harassment $(1 \%)$, and physical violence $(1 \%)$. In the working population of German-speaking Switzerland, intimidation or mobbing was also the most frequently reported form of violence $(7 \%)$. In comparison with other occupational groups, nurses and midwives were by far the most affected from all forms of violence.

Overall, almost a quarter (23\%) of the surveyed hospital employees reported at least one form of discrimination or violence in the past year, whereby nurses and midwives were most frequently affected (24\%), followed by physicians and other academic staff $(23 \%)$, medicaltherapeutic and medical-technical staff $(21 \%)$ and administrative and other service staff (19\%). 
Hospital employees and particularly health professionals were found to be more frequently

251 affected by experiences of violence and discrimination at work than employed persons and

252 working people in general, which make such experiences at work on average in "only" $18 \%$ of

253 the cases.

254

\section{Table 1}

256 One-year prevalence of workplace discrimination and violence among occupational groups of

257 hospital employees

\begin{tabular}{|c|c|c|c|c|c|c|}
\hline & $\begin{array}{c}\begin{array}{c}\text { Nurses } \\
\text { and } \\
\text { midwives }\end{array} \\
(\mathrm{N}=718)\end{array}$ & $\begin{array}{l}\text { Physicians } \\
\text { and other } \\
\text { academic } \\
\text { staff } \\
(\mathrm{N}=293)\end{array}$ & $\begin{array}{c}\text { Medical- } \\
\text { therapeutic } \\
\text { and } \\
\text { medical- } \\
\text { technical } \\
\text { staff } \\
(N=221)\end{array}$ & $\begin{array}{l}\text { Administrat } \\
\text { ive and } \\
\text { other } \\
\text { service } \\
\text { staff } \\
(\mathrm{N}=325)\end{array}$ & $\begin{array}{c}\text { Total } \\
\text { hospital } \\
\text { employees } \\
(N=1,557)\end{array}$ & $\begin{array}{c}\text { Working } \\
\text { population } \\
\text { of German- } \\
\text { speaking } \\
\text { Switzerland } \\
(\mathrm{N}=8,281)^{1)}\end{array}$ \\
\hline \multicolumn{7}{|l|}{ Forms of violence } \\
\hline Verbal abuse & $9.3 \%$ & $6.8 \%$ & $3.6 \%$ & $4.6 \%$ & $7.1 \%$ & $4.7 \%$ \\
\hline $\begin{array}{l}\text { Threats and } \\
\text { humiliation }\end{array}$ & $6.1 \%$ & $5.1 \%$ & $4.5 \%$ & $4.0 \%$ & $5.3 \%$ & $4.1 \%$ \\
\hline Physical violence & $1.7 \%$ & $0.3 \%$ & $0.5 \%$ & $0.0 \%$ & $0.9 \%$ & $1.1 \%$ \\
\hline $\begin{array}{l}\text { Intimidation or } \\
\text { mobbing }\end{array}$ & $11.3 \%$ & $8.2 \%$ & $8.5 \%$ & $8.9 \%$ & $10.0 \%$ & $6.5 \%$ \\
\hline Sexual harassment & $1.5 \%$ & $0.7 \%$ & $0.0 \%$ & $0.6 \%$ & $1.0 \%$ & $0.8 \%$ \\
\hline \multicolumn{7}{|c|}{ Forms of discrimination } \\
\hline Due to age & $4.5 \%$ & $4.4 \%$ & $4.1 \%$ & $6.2 \%$ & $4.8 \%$ & $5.7 \%$ \\
\hline Due to gender & $2.9 \%$ & $8.2 \%$ & $4.5 \%$ & $2.5 \%$ & $4.0 \%$ & $3.9 \%$ \\
\hline $\begin{array}{l}\text { Due to nationality, } \\
\text { ethnicity or skin color }\end{array}$ & $2.2 \%$ & $4.1 \%$ & $1.8 \%$ & $2.5 \%$ & $2.6 \%$ & $3.4 \%$ \\
\hline Due to disability & $0.3 \%$ & $0.0 \%$ & $0.9 \%$ & $0.6 \%$ & $0.4 \%$ & $0.8 \%$ \\
\hline \multicolumn{7}{|c|}{ Total number of different forms of violence and/or discrimination } \\
\hline None $(0)$ & $75.6 \%$ & $76.8 \%$ & $78.7 \%$ & $80.9 \%$ & $77.4 \%$ & $81.7 \%$ \\
\hline One (1) & $14.3 \%$ & $13.0 \%$ & $14.9 \%$ & $10.5 \%$ & $13.4 \%$ & $10.6 \%$ \\
\hline Accumulated $(2+)$ & $10.0 \%$ & $10.2 \%$ & $6.3 \%$ & $8.6 \%$ & $9.2 \%$ & $7.7 \%$ \\
\hline
\end{tabular}

1)Based on weighted and extrapolated data from the Swiss Health Survey 2017 
Table 2 illustrates the associations between the experience of workplace violence and/or discrimination and different dimensions of health among hospital employees: After adjusting for sex, age, education (control variables) and chronic disease (potential confounding variable), experiencing one single form of discrimination or violence at work (compared to having not experienced any violence or discrimination) was significantly associated with strong sleep disorders (19\% vs. $11 \%$, aOR 2.0$)$, strong psychological stress (19\% vs. $11 \%$, aOR 1.7$)$ and increased burnout symptoms ( $14 \%$ vs. $6 \%$, aOR 2.6$)$. These associations were clearly more pronounced when having reported accumulated experiences of workplace violence and/or discrimination, i.e. more than one form. These most affected or exposed hospital employees show almost consistently - although not always significantly - the highest prevalence rate and relative risk for poor self-rated health (17\%, aOR 1.6), strong sleep disorders $(29 \%$, aOR 3.1$)$, strong psychological stress (33\%, aOR 3.4), being treated for a mental problem (12\%, aOR 1.4) or increased burnout symptoms (21\%, aOR 4.1$)$, compared to those who have not made any of such experiences at all. The initially clear and statistically significant dose-response relationship or gradient found for poor self-rated health in the simple model turned into a non-significant association and a non-linear relationship in the extended model including the potentially confounding variable of chronic disease. Only for having a mental problem, prevalence rates and adjusted odds ratios as proxies for the relative risk were not significantly increased for the most affected and exposed from the very beginning and in both models.

In other words, a strong association and clear and stable dose-response relationship was observed between the number of experiences of workplace violence and/or discrimination and three of the five studied health outcomes. And this relationship was not substantially confounded by chronic disease (extended model) which in turn was found to be a strong and significant risk factor of poor general and mental health outcomes itself.

\section{Table 2}

Associations between workplace violence and/or discrimination and health measures among hospital employees $(\mathrm{N}=1,567)$ 


\begin{tabular}{|c|c|c|c|c|c|c|c|c|c|c|c|c|c|c|c|}
\hline & \multicolumn{3}{|c|}{$\begin{array}{c}\text { Poor } \\
\text { self-rated health }\end{array}$} & \multicolumn{3}{|c|}{$\begin{array}{c}\text { Strong } \\
\text { sleep disorders }\end{array}$} & \multicolumn{3}{|c|}{$\begin{array}{c}\text { Strong } \\
\text { psychological stress }\end{array}$} & \multicolumn{3}{|c|}{$\begin{array}{l}\text { Being treated for } \\
\text { mental problem }\end{array}$} & \multicolumn{3}{|c|}{$\begin{array}{c}\text { Increased } \\
\text { burnout symptoms }\end{array}$} \\
\hline & $\%$ & $\mathrm{aOR}^{1)}$ & $95 \% \mathrm{Cl}$ & $\%$ & $\mathrm{aOR}^{1)}$ & $95 \% \mathrm{Cl}$ & $\%$ & $\mathrm{aOR}^{1)}$ & $95 \% \mathrm{Cl}$ & $\%$ & $\mathrm{aOR}^{1)}$ & $95 \% \mathrm{Cl}$ & $\%$ & $\mathrm{aOR}^{1)}$ & $95 \% \mathrm{Cl}$ \\
\hline Total study population & 11.1 & & & 13.3 & & & 14.3 & & & 7.5 & & & 8.4 & & \\
\hline \multicolumn{16}{|l|}{ MODEL 1 (simple) } \\
\hline \multicolumn{16}{|l|}{$\begin{array}{l}\text { Workplace violence } \\
\text { and/or discrimination }\end{array}$} \\
\hline None $(0)$ & 9.6 & 1 & & 10.6 & 1 & & 11.3 & 1 & & 7.3 & 1 & & 5.8 & 1 & \\
\hline One (1) & 15.2 & $1.68^{*}$ & $1.10-2.56$ & 18.6 & $1.92^{* * *}$ & $1.30-2.85$ & 18.9 & $1.82^{* *}$ & $1.22-2.71$ & 5.8 & 0.79 & $0.42-1.46$ & 14.4 & $2.71^{* \star *}$ & $1.72-4.28$ \\
\hline Accumulated $(2+)$ & 17.4 & $1.97^{\star *}$ & $1.23-3.16$ & 28.5 & $3.36^{\star \star *}$ & $2.24-5.04$ & 33.1 & $3.86^{\star * *}$ & $2.60-5.75$ & 11.8 & 1.71 & $0.98-2.96$ & 21.1 & $4.33^{\star \star *}$ & $2.70-6.93$ \\
\hline No. of cases in model & \multicolumn{3}{|c|}{1,559} & \multicolumn{3}{|c|}{1,552} & \multicolumn{3}{|c|}{1,507} & \multicolumn{3}{|c|}{1,548} & \multicolumn{3}{|c|}{1,535} \\
\hline \multicolumn{16}{|l|}{ MODEL 2 (extended) } \\
\hline \multicolumn{16}{|l|}{$\begin{array}{l}\text { Workplace violence } \\
\text { and/or discrimination }\end{array}$} \\
\hline None $(0)$ & 9.6 & 1 & & 10.6 & 1 & & 11.3 & 1 & & 7.3 & 1 & & 5.8 & 1 & \\
\hline One (1) & 15.2 & 1.59 & $1.00-2.54$ & 18.6 & $1.97^{* \star *}$ & $1.31-2.95$ & 18.9 & $1.74^{* *}$ & $1.15-2.62$ & 5.8 & 0.68 & $0.36-1.31$ & 14.4 & $2.55^{* * *}$ & $1.60-4.07$ \\
\hline Accumulated $(2+)$ & 17.4 & 1.57 & $0.93-2.64$ & 28.5 & $3.11^{* * *}$ & $2.03-4.74$ & 33.1 & $3.37^{* \star *}$ & $2.23-5.08$ & 11.8 & 1.44 & $0.81-2.56$ & 21.1 & $4.11^{* * *}$ & $2.53-6.66$ \\
\hline Chronic disease & & & & & & & & & & & & & & & \\
\hline No & 4.4 & 1 & & 10.5 & 1 & & 11.5 & 1 & & 5.7 & 1 & & 6.9 & 1 & \\
\hline Yes & 29.8 & $9.54^{* * *}$ & $6.62-13.74$ & 21.2 & $1.98^{* * *}$ & $1.44-2.72$ & 22.8 & $2.05^{\star \star *}$ & $1.50-2.80$ & 12.3 & $2.29^{\star \star *}$ & $1.54-3.40$ & 12.7 & $1.87^{* *}$ & $1.26-2.75$ \\
\hline No. of cases in model & \multicolumn{3}{|c|}{1,515} & \multicolumn{3}{|c|}{1,509} & \multicolumn{3}{|c|}{1,462} & \multicolumn{3}{|c|}{1,505} & \multicolumn{3}{|c|}{1,493} \\
\hline
\end{tabular}

$289{ }^{*} p<0.05,{ }^{* *} p<0.01,{ }^{* * *} p<0.001$

290 1)Odds ratios adjusted for sex, age and education (control variables) 


\section{Discussion}

One purpose of this study was to assess the frequency of workplace violence and discrimination among hospital employees and particular health professions in a hospital setting in Germanspeaking Switzerland. Almost every fourth (23\%) of the study population reported at least one form of discrimination or violence at work in the past 12 months before the survey, compared to only every sixth (18\%) in the entire working population of German-speaking Switzerland. With a view to the occupational groups, nurses and midwives were most often affected by violence at work, whereas physicians and other academics were most often affected by discrimination due to nationality, ethnicity or skin color and particularly due to gender. The most frequent form of violence among hospital employees was intimidation or mobbing $(10 \%)$, whereas ageism was the most commonly reported type of discrimination (5\%). Hence, the finding of a comparably high prevalence of workplace violence and discrimination in hospital employees compared with the general working population is in accordance with previous research, which has shown that health care workers are at special risk for workplace violence, as they work with people who are in distress (6). Working in direct patient contact means to be faced with people whose behavior can be affected by acute illness and pain, psychiatric and neurological disorders, intoxications and substance abuse $(6,21)$. Nurses are at particular risk, as this is usually the professional group temporally most exposed to patients (22). There is also evidence that certain hospital units are more confronted with violence from patients or visitors, such as emergency departments and psychiatric wards $(23,24)$. Intimidation or mobbing in this study was found to be the most commonly reported form of workplace violence and twice as often than in another study conducted in nursing homes in Switzerland, which found a prevalence of mobbing in the past 6 months of nearly $5 \%$ among care workers (25). Regarding ageism, earlier studies showed that discrimination on the grounds of being "too young" is at least as common as on the grounds of being "too old" (26). Although employees of these two age groups are confronted with different prejudices and potential occupational disadvantages, there is evidence that ageism is associated with a lower level of affective 
commitment in both of them (26). Another finding of this study is that gender discrimination is most commonly reported among physicians and other academic staff. A possible explanation might be that this form of discrimination is becoming increasingly important in employees with higher education. Equal rights for women and men and gender equality is an important concern in politics and policies since many years in Switzerland (27). However, with a look at the Gender Monitoring Report from Swiss University faculties of medicine in 2014, there is still a considerable gender gap in higher positions: While over $50 \%$ of medical graduates with a master's degree are women, the proportion drops to $10 \%$ on full professor level (28).

With a look at the one-year prevalence of violence expected by health personal in an international comparison, a very broad range can be observed, ranging from $3 \%$ (Portugal) to $17 \%$ (South Africa) for physical attacks, from 17\% (Portugal) to $67 \%$ (Austria) for verbal violence and from $11 \%$ (Australia) to $31 \%$ (Bulgaria) for mobbing (6). One reason for these large differences between countries might be a limited comparability of the underlying studies, for example in relation to the methodology (study design, definitions used), setting (differences in health care systems, hospital versus outpatient sector, medical specialties), sample (personal characteristics of the study population) and cultural peculiarities (including differences in awareness and reporting systems).

Besides increased prevalence rates of specific forms of violence and/or discrimination at work and/or among particular occupational groups, accumulated experiences of workplace violence and/or discrimination among hospital employees and particularly health professionals were found to be strongly associated with poor mental health outcomes such as strong sleep disorders, strong stress feelings or increased burnout symptoms. The prevalence (or relative frequency) and the odds or likelihood (or relative risk) of these poor health outcomes were shown to gradually, substantially and significantly increase with the self-reported number of experiences $(0,1,2+)$ of violence and/or discrimination made at work, suggesting a doseresponse relationship. The strength of association and the clear dose-response relationship across most studied outcomes are a good indication for a causal relationship. 
This finding is in line with a series of earlier international studies and findings and particularly supported by a systematic literature review from Canada published in 2013 on the consequences of workplace violence among health care workers, showing a significant association with psychological problems in 47 studies (13). The majority of the considered studies reported symptoms of a posttraumatic stress disorder (such as intrusion, negative changes in cognition or mood, changes in arousal and reactivity, sleep disturbances) and depressive symptoms (13). Ten studies reported a negative effect on self-reported mental health, while psychological distress was reported to be higher in five studies (13). A previous study among Swiss nursing home care workers found a remarkably higher odds of health complaints in those directly affected by mobbing (25). Another study on the consequences of workplace violence among Chinese physicians showed a positive correlation with psychological stress, and a negative association with subjective sleep quality and subjective health (29). Partly in contrast to this Chinese study, we did not find a significant association of experienced violence or discrimination at work with self-reported health, at least not after adjusting for chronic disease. In other words: Although prevalence rates of poor self-rated health were significantly increased among hospital employees who experience and report at least one form of violence and/or discrimination at work, this was mainly due to their higher proportion of chronically diseased who in turn showed an almost tenfold higher risk of being in poor general and self-reported health than those without a chronic disease. Regarding the other studied poor health outcomes, chronic disease not turned out to be an important confounder, as having a chronic disease only about doubled (and not tenfold increased) the risk of having strong sleep disorders, feeling strong psychological stress, being treated for a mental problem or showing increased burnout symptoms. For these health measures, chronic disease only slightly explained and therefore reduced the strong association found between workplace violence or discrimination and poor health outcomes. But in case of poor self-rated health, a gradually and significantly increased risk with the increasing number of experiences of violence and discrimination at work turned out to be not statistically significant anymore when the association was adjusted for chronic disease. 
375 In sum - it is not really surprising but at the same time has not been shown before at least for

376 health care workers in Switzerland - we found that accumulated experiences of violence and

377 discrimination at work are a strong stressor and risk factor for sleep disorders, psychological

378 stress and burnout, even though it does not seem to cause severe mental problems.

Burnout symptoms in health care workers are very common. A meta-analysis among medical and surgical residents estimates its global prevalence to be around $51 \%(30)$. Burnout is a psychological syndrome, which can be regarded as a prolonged result to chronic stressors at work, consisting of three different domains, namely emotional exhaustion, depersonalization and low personal achievement (31). It seems to be more prevalent in professions comprising an intensive work with other people, such as care giving or teaching roles (31). As burnout in health care staff is associated with higher costs and major medical errors (32), studies investigating its risk factors are numerous. Previous studies suggest that mistreatment of health care professionals (including harassment, bullying, discrimination and physical violence) contribute to the development of burnout symptoms in this population (33-35). However, there is a broad range of other factors related to health care organizations and systems as well as individual characteristics knowing to play an important role in the development of or protection from burnout symptoms (36).

\section{Limitations}

This study has some limitations that have to be considered with regard to the study results:

First, the study is based on cross-sectional data, which do not allow to test for causality.

Moreover, reverse causality cannot be excluded either. For instance, a high level of stress can trigger unsocial behavior towards colleagues or impatient behavior towards patients, which themselves could increase the risk of discriminating statements from colleagues or aggressive behavior in patients. This raises the question whether psychological stress is a consequence of discrimination or violence experiences or if a high stress level could also be the starting point of a vicious circle ending in violence or discrimination experiences. 
Secondly, the question measuring experiences of workplace violence or discrimination did not

distinguish between internal and external violence and did not assess the true extent of the experiences, which would have been helpful for a more accurate estimation of the exposure or strain and for the interpretation of the results. Additionally, there is a risk for potential recall bias, as the question on experienced violence and discrimination refers to a period of 12 months before completion of the questionnaire.

In view of the described overall response rate of around $41 \%$, there is a risk for potential selection bias (non-response bias). Also, as participants were allowed to complete the questionnaire during working time, a potential response bias should be taken into account, as people could have answered in a way they considered to be desirable by their company.

\section{Conclusions}

Having in mind the negative consequences of workplace violence and discrimination on mental health, the present study underlines the importance of an active combat against these undesired but still common behaviors in the health care setting. Managing violence and discrimination at workplace is a challenging task not only for clinical practice, but also for health policy, requiring a holistic approach according to the complexity of these phenomenon.

Therefore, prevention and dealing strategies in hospitals should not only focus on organizational factors, but also on the level of the individual employees and their interactions. With regard to the latter, previous studies suggest to provide training programs for health care workers, for example in communication skills (37). With regard to organizational factors in hospitals, the development of a no-tolerance policy or environmental changes improving the safety (e.g. the presence of security systems) are some examples which are assumed to limit workplace violence (21). However, another important issue is the way how to handle discrimination or violence experiences that have already taken place, in a way that minimizes its negative consequences on the victims. For example, Schat and Kelloway found that social support from colleagues and supervisors is able to buffer the negative consequence of workplace 
431 violence/aggression on physical and psychological health as well as working attitudes in health

432 care employees (38).

434 The comparably high prevalence of violence and discrimination among hospital staff and

435 particularly among health professionals and its significant association with sleep disorders,

436 stress feelings and burnout symptoms underline the importance of an active combat against

437 these behaviors in health care. Strategies to prevent violence should primarily focus on nurses

438 and midwives, which have been identified as the most affected professional group of hospital

439 employees in this study.

\section{$441 \quad$ List of abbreviations}

443 aOR adjusted odds ratio

$444 \mathrm{CBI} \quad$ Copenhagen Burnout Inventory

$445 \quad \mathrm{Cl} \quad 95 \%$ Confidence Interval

446 FOPH Federal Office of Public Health

447 ILO International Labour Organization

448 SECO State Secretariat of Economic Affairs

$449 \quad \mathrm{SRH} \quad$ Self-rated health

450 SUVA Swiss National Accident Insurance Fund

\section{Declarations}

\section{Ethics approval and consent to participate}

This study is observational and not clinical or experimental. Self-reported data used were collected from hospitals and rehabilitation clinics, but survey respondents were employees and not patients. Furthermore, participation in the survey was voluntary and anonymous. 
conclusions on their identity. For all these reasons, informed and explicit consent from respondents was not needed or obtained but implicitly given by participating voluntarily in the survey.

The study and survey were carried out in accordance with the Declaration of Helsinki. The study was exempted from requiring ethical approval because the used data do not fall within the scope of the Swiss Federal Act on Research involving Human Beings whose purpose is to protect the dignity, privacy and health of human beings involved in research. This so-called Human Research Act (HRA) explicitly declares in Art. 2 that it does NOT apply to research which involves anonymously collected or subsequently anonymized health-related data. Since the data used were no register data and did not involve medical records or human tissues from patients but instead were self-reports from employees and collected completely anonymously, so that they cannot be traced to a specific person, no formal approval or authorization of the study is required or will be issued, neither by the cantonal ethics committees nor by the cantonal commissioners for data protection. This is not even recommended by the medical-ethical guidelines for scientific integrity of the Central Ethics Committee and the Swiss Academies of Sciences.

\section{Consent for publication}

This manuscript does not include details, images, or videos relating to an individual person, therefore no written informed consent for the publication of these details must be obtained from the study participants.

\section{Availability of data and materials}

Individual data were collected by random and full sample surveys among the workforces of several public hospitals and rehabilitation clinics. Data were collected anonymously and on a voluntary basis. However, data are not publicly accessible and freely available since the use and analysis of the pooled data and the publication of any research findings and study results out of it are restricted by contract with the participating companies (hospitals, clinics) to the 
487 University of Zurich (Epidemiology, Biostatistics and Prevention Institute) and the collaborating

488 Careum Research, a division of the Careum Foundation. As contracted, the use of the data is 489 basically limited to the two research institutions and disclosure and delivery of the data therefore

490 is not permitted. In order to get an exceptional permission and possible conditional access to

491 the survey data for scientific purposes the corresponding author as the principal investigator and the responsible for the data collection needs to be contacted.

493

494

Competing interests

495

The authors declare that there are no competing interests.

496

497 Funding

498 This study received no funds from any third-party donor or funding institution in the public,

499 commercial, or non-profit sectors.

500

\section{Authors' contributions}

502

503

504

505

506

507

508

ASG drafted the raw version of the manuscript and contributed to the statistical analysis of the data. $\mathrm{OH}$ collected and analyzed the data and revised the manuscript. Both authors equally conceptualized the study and interpreted the findings, and read and approved the final manuscript.

\section{Acknowledgements}

Not applicable 


\section{References}

510

511 1. Chappell D, Di Martino V. Patterns and trends. In: Violence at work. Third edition. Geneva:

512 International Labour Office; 2006: 29-70.

$5132 . \quad$ International Labour Conference. Equality at work: The continuing challenge - Global

514 Report under the follow-up to the ILO Declaration on Fundamental Principles and Rights at Work.

515 Geneva: ILO; 2011 Nov. 70 p. ISBN: 978-92-2-123092-2.

$5163 . \quad$ International Labour Organization. Code of practice on workplace violence in services

517 sectors and measures to combat this phenomenon. Geneva: ILO; 2003 Oct. 20 p. .

518 4. Interational Labour Organization. Übereinkommen 111: Übereinkommen über die

519 Diskriminierung in Beschäftigung und Beruf, 1958 [Internet]; 1960 [date unknown; cited 2021 Sep

520 19]. Available from: https://www.ilo.org/wcmsp5/groups/public/---ed_norm/---

521 normes/documents/normativeinstrument/wcms_c111_de.htm.

522 5. Beech B, Leather P. Workplace violence in the health care sector: A review of staff training 523 and integration of training evaluation models. Aggression and Violent Behavior. 2006;11(1):2752443.

525 6. Chappell D, Di Martino V. Ocupations and situations at risk. In: Violence at work. Third 526 edition. Geneva: International Labour Office; 2006: 71-109.

527 7. Carr PL, Ash AS, Friedman RH, Szalacha L, Barnett RC, Palepu A, et al. Faculty 528 perceptions of gender discrimination and sexual harassment in academic medicine. Annals of 529 internal medicine. 2000;132(11):889-96.

530 8. Thrasher AD, Wells AM, Spencer SM, Cofie L, Yen IH. Workplace Discrimination Is 531 Associated With Alcohol Abuse Among Ethnically Diverse Hospital Staff. Workplace health \& 532 safety. 2016;64(5):202-9.

533 9. Arnetz JE, Hamblin L, Ager J, Luborsky M, Upfal MJ, Russell J, et al. Underreporting of 534 Workplace Violence: Comparison of Self-Report and Actual Documentation of Hospital Incidents. 535 Workplace health \& safety. 2015;63(5):200-10. 
536 10. Kvas A, Seljak J. Unreported workplace violence in nursing. International nursing review.

$537 \quad 2014 ; 61(3): 344-51$.

538 11. Sato K, Wakabayashi T, Kiyoshi-Teo H, Fukahori H. Factors associated with nurses' 539 reporting of patients' aggressive behavior: a cross-sectional survey. International journal of 540 nursing studies. 2013;50(10):1368-76.

541 12. Baby M, Glue P, Carlyle D. 'Violence is not part of our job': a thematic analysis of 542 psychiatric mental health nurses' experiences of patient assaults from a New Zealand 543 perspective. Issues in mental health nursing. 2014;35(9):647-55.

544 13. Lanctôt N, Guay S. The aftermath of workplace violence among healthcare workers: A 545 systematic literature review of the consequences. Aggression and Violent Behavior. $546 \quad 2014 ; 19(5): 492-501$.

547 14. Triana MdC, Jayasinghe M, Pieper JR, Delgado DM, Li M. Perceived Workplace Gender 548 Discrimination and Employee Consequences: A Meta-Analysis and Complementary Studies 549 Considering Country Context. Journal of Management. 2018;45(6):2419-47.

550 15. Bundesamt für Statistik (BFS). Schweizerische Gesundheitsbefragung 2017 - Übersicht. 551 Neuchâtel: BFS; 2018 Dec. 26 p. BFS-Number: 213-1701.

552 16. Idler EL, Benyamini Y. Self-rated health and mortality: a review of twenty-seven 553 community studies. Journal of health and social behavior. 1997;38(1):21-37.

554 17. Latham K, Peek CW. Self-rated health and morbidity onset among late midlife U.S. adults.

555 The journals of gerontology Series B, Psychological sciences and social sciences. $5562013 ; 68(1): 107-16$.

557 18. Manor O, Matthews S, Power C. Dichotomous or categorical response? Analysing self558 rated health and lifetime social class. International journal of epidemiology. 2000;29(1):149-57.

559 19. Elo A-L, Leppänen A, Jahkola A. Validity of a single-item measure of stress symptoms. 560 Scandinavian Journal of Work, Environment \& Health. 2003(6):444-51.

561 20. Kristensen TS, Borritz M, Villadsen E, Christensen KB. The Copenhagen Burnout 562 Inventory: A new tool for the assessment of burnout. Work \& Stress. 2005;19(3):192-207. 
21. Gillespie GL, Gates DM, Miller M, Howard PK. Workplace Violence in Healthcare Settings:

Risk Factors and Protective Strategies. Rehabilitation Nursing Journal. 2010;35(5):177-84.

22. Phillips JP. Workplace Violence against Health Care Workers in the United States. The New England journal of medicine. 2016;374(17):1661-9.

23. Kowalenko T, Walters BL, Khare RK, Compton S. Workplace violence: a survey of emergency physicians in the state of Michigan. Annals of emergency medicine. 2005;46(2):1427.

24. Arnetz JE, Aranyos D, Ager J, Upfal MJ. Development and application of a populationbased system for workplace violence surveillance in hospitals. American journal of industrial medicine. 2011;54(12):925-34.

25. Tong M, Schwendimann R, Zúñiga F. Mobbing among care workers in nursing homes: A cross-sectional secondary analysis of the Swiss Nursing Homes Human Resources Project. International journal of nursing studies. 2017;66:72-81.

26. Snape E, Redman T. Too old or too young? The impact of perceived age discrimination. Human Resource Management Journal. 2003;13(1):78-89.

27. Ziegler B. Some remarks on gender equality in higher education in Switzerland. International Journal of Sociology and Social Policy. 2001;21(1/2):44-9.

28. Lerch-Pieper N, Brander S, Valarino I, Zurbriggen C, Maurer E, Herr W, et al. Challenging the "leaky pipeline" in faculties of medicine [Internet]. Muttenz (BL): Swiss Medical Weekly; 2017 May 12 [cited 2021 Sep 19]. Available from: https://smw.ch/opeds?tx_swablog_postdetail\%5Bpost $\% 5 \mathrm{D}=59$.

29. Sun T, Gao L, Li F, Shi Y, Xie F, Wang J, et al. Workplace violence, psychological stress, sleep quality and subjective health in Chinese doctors: a large cross-sectional study. BMJ open. 2017;7(12):e017182.

30. Low ZX, Yeo KA, Sharma VK, Leung GK, Mclntyre RS, Guerrero A, et al. Prevalence of Burnout in Medical and Surgical Residents: A Meta-Analysis. International journal of environmental research and public health. 2019;16(9). 
590 31. Maslach C, Schaufeli WB, Leiter MP. Job burnout. Annual review of psychology. $591 \quad 2001 ; 52: 397-422$.

592 32. Patel RS, Sekhri S, Bhimanadham NN, Imran S, Hossain S. A Review on Strategies to 593 Manage Physician Burnout. Cureus. 2019;11(6):e4805.

594 33. Kemper KJ, Schwartz A. Bullying, Discrimination, Sexual Harassment, and Physical 595 Violence: Common and Associated With Burnout in Pediatric Residents. Academic Pediatrics. $596 \quad 2020 ; 20(7): 991-7$.

597 34. Yang BX, Stone TE, Petrini MA, Morris DL. Incidence, Type, Related Factors, and Effect 598 of Workplace Violence on Mental Health Nurses: A Cross-sectional Survey. Archives of 599 Psychiatric Nursing. 2018;32(1):31-8.

600 35. Viotti S, Gilardi S, Guglielmetti C, Converso D. Verbal Aggression from Care Recipients 601 as a Risk Factor among Nursing Staff: A Study on Burnout in the JD-R Model Perspective. BioMed 602 research international. 2015;2015:215267.

603 36. West CP, Dyrbye LN, Shanafelt TD. Physician burnout: contributors, consequences and 604 solutions. Journal of Internal Medicine. 2018;283(6):516-29.

605 37. D'Ettorre G, Pellicani V, Mazzotta M, Vullo A. Preventing and managing workplace 606 violence against healthcare workers in Emergency Departments. Acta bio-medica : Atenei 607 Parmensis. 2018;89(4-s):28-36.

608 38. Schat AC, Kelloway EK. Reducing the adverse consequences of workplace aggression 609 and violence: the buffering effects of organizational support. Journal of occupational health 610 psychology. 2003;8(2):110-22. 